\title{
Ação coletiva e coprodução para o desenvolvimento rural: um estudo de caso do Colegiado de Desenvolvimento Territorial da Serra Catarinense
}

\author{
Alexandre Coimbra Ribeiro \\ Empresa de Pesquisa Agropecuária e Extensão Rural de Santa Catarina (Epagri) \\ Carolina Andion \\ Centro de Ciências da Administração e Socioeconômicas (Esag) da Universidade do Estado de Santa \\ Catarina (Udesc) \\ Fábio Burigo \\ Centro de Ciências Agrárias (CCA) da Universidade Federal de Santa Catarina (UFSC)
}

\begin{abstract}
Este artigo analisa a ação coletiva promovida pelo Colegiado de Desenvolvimento Territorial (Codeter) da Serra Catarinense, buscando verificar se essa ação colaborou para mobilizar um processo de coprodução do bem público no planejamento e gestão do desenvolvimento rural no território. Foi empregada uma estratégia de investigação de estudo de caso que combinou a utilização de diversas técnicas qualitativas de coleta de dados, análise e interpretação dos resultados. Diferentes paradigmas que tratam da ação coletiva foram considerados, no intuito de examinar a ação concertada promovida no Codeter e suas características principais. Com base no conceito de coprodução e suas variáveis, verificamos que essa ação coletiva engendrou um novo tipo de ação pública, ampliando a participação e a colaboração entre os atores sociais na coconstrução de soluções para os problemas públicos do território.
\end{abstract}

Palavras-chave: desenvolvimento rural; ação coletiva; coprodução do bem público.

Acción colectiva y coproducion para el desarrollo rural: un estudio de caso de Codeter de la Sierra Catarinense

En este artículo se analiza la acción colectiva promovida por el Colegio de Desarrollo Territorial (Codeter) de la Sierra Catarinense, tratando de verificar si esta acción ayudó a movilizar un proceso de co-producción de bienes públicos en la planificación y gestión del desarrollo rural en el territorio. Se utilizó un estudio de caso como estrategia de investigación y una combinación de diversas técnicas cualitativas de recolección de datos, análisis e interpretación de resultados. Diferentes paradigmas que tienen que ver con la acción colectiva se consideraron con el fin de examinar la concertación

DOI: http://dx.doi.org/10.1590/0034-76121685

Artigo recebido em 12 ago. 2013 e aceito em 11 ago. 2014.

(cc) BY-NC 
promovida por el Codeter y sus principales características. Basado en el concepto de co-producción y sus variables, nos encontramos que esta acción colectiva ha generado un nuevo tipo de acción pública, con la ampliación de la participación y la colaboración entre los actores sociales en la co-construcción de soluciones a los problemas comunes del territorio.

Palabras clave: desarrollo rural; acción colectiva; coproducción de bienes públicos.

Colective action and co-production for the rural development: a case study of Codeter in Santa Catarina mountain range

This article analyzes the collective action of Codeter (Colegiado de Desenvolvimento Territorial - Territorial Development Collegiate) which is located in Santa Catarina mountain range, in Brazil. It aims to verify if this action contributed to mobilize a process of coproduction of public goods in the planning and management of rural development in the territory. A combined case study strategy was employed which featured diverse qualitative techniques of data collection, analysis and interpretation of the results. Different paradigms of collective action were considered, in order to examine the concerted action promoted by Codeter and its main features. Furthermore, based on the concept of coproduction and its variables, we could understand that this collective action promoted a new kind of public action, deepening the participation and collaboration of different social actors in the co-construction of solutions to the public problems of the territory.

KEYWORDs : rural development; collective action; coproduction of public goods.

\section{Introdução}

A partir do final da década de 1980, diversas mudanças estruturais e sociopolíticas ocorreram na esfera pública do Brasil, impulsionadas, em grande parte, pelo processo de redemocratização do país, a partir da promulgação da Constituição Federal de 1988. Dentre essas mudanças, cabe citar: a descentralização do poder federal para as esferas estaduais e municipais; a municipalização de diversas políticas e serviços públicos; o aumento da participação da sociedade civil na esfera pública e a inserção de questões até então pouco relevantes na agenda política, a exemplo da diminuição das desigualdades sociais e da preservação ambiental.

Todas essas mudanças desencadearam transformações significativas no meio rural brasileiro, impulsionando questionamentos sobre o modelo de desenvolvimento rural adotado no país, durante a fase de modernização de sua agropecuária (Freitas et al., 2012). Tal modelo, também denominado Revolução Verde, foi introduzido no país a partir dos anos 1960, mas não gerou as modificações esperadas na estrutura fundiária brasileira. Sem alterar o perfil altamente concentrado das terras brasileiras, as ações da modernização agrícola estavam principalmente focadas na expansão das culturas e da pecuária de alto valor comercial. Foi nesse sentido que se direcionou o investimento para a criação de estruturas de pesquisa, ensino e extensão agronômicas e a oferta de crédito, favorecendo a introdução maciça de insumos químicos, irrigação e "tratorização" dos cultivos. O incremento da monocultura pressupunha 
também a desvalorização dos conhecimentos tradicionais e o abandono dos sistemas de produção baseados na diversificação. Embora se reconheça que esse modelo gerou aumentos na produção e na renda agrícola, favorecendo o surgimento de alguns polos econômicos regionais e o aumento da oferta de alimentos nas cidades, não apresentou soluções satisfatórias para o problema da pobreza rural e nem para o baixo dinamismo socioeconômico da maioria das regiões interioranas do país.

No início dos anos 2000, as críticas ao modelo de modernização conservadora do campo brasileiro ganham amplitude, por meio da introdução definitiva das questões ambientais na agenda pública e do (re) surgimento da noção de território no âmbito do planejamento rural. Criam-se, então, os ingredientes fundamentais para a discussão sobre a "nova ruralidade" e para a urgência de se construírem propostas concretas que resultem no ecodesenvolvimento das zonas rurais (Sachs, 2001). Como destacam Ferreira e Zanoni (1998), se antes a prioridade era levar ao campo as inovações tecnológicas e outras necessidades subjacentes à vida moderna, agora a questão seria promover um desenvolvimento de novo tipo. Nesse momento, os papéis desempenhados pelos atores que vivem no campo ou se relacionam diretamente com o meio rural, em especial os ligados à agricultura familiar, ganham maior relevância.

Diversos autores discutem a importância de se "redescobrir o rural", valorizando suas particularidades socioeconômicas e as outras funções existentes nesse espaço. Nessa perspectiva, o meio rural não é apenas um espaço produtivo, mas um espaço de vida, portador de uma identidade própria e capaz de gerar inovações e novas oportunidades de desenvolvimento (Abramovay, 1998, 1999, 2010; Sachs, 2001; Sabourin, 2002; Schneider, 2003; Veiga, 2002a, 2002b).

Nesse contexto, emerge o conceito de Desenvolvimento Territorial Sustentável (DTS), um novo modo de conceber o planejamento regional, aliando múltiplos objetivos, ligados à busca da equidade social, preservação ambiental, eficiência econômica e democracia política. O DTS vincula o planejamento participativo de gestão com o caráter intermunicipal das iniciativas (Andion, 2010; Jean, 2010; Vieira et al., 2010a). Dando relevo aos ativos do mundo rural para além da agricultura, a abordagem do DTS procura desmistificar a clivagem que tradicionalmente separa os mundos rural e urbano. Como explicam Zanoni e Lamarche (2001), longe da ideia de um rural fadado a desaparecer e a se dissolver no urbano, o desenvolvimento sustentável dos territórios pressupõe duas dinâmicas paralelas: uma rural e outra urbana, essas dinâmicas são complementares e alimentam-se mutuamente.

Ao estabelecer uma nova relação entre campo e cidade e romper com a visão setorial que confunde o rural com agrícola, a leitura da sustentabilidade dos territórios rurais coloca também em xeque a visão tradicional pelo qual os espaços rurais são "vazios sociais", ou seja, espaços de isolamento cultural e de abandono. Essa nova interpretação sobre o mundo rural busca romper com uma visão desses espaços como "vestígios do passado", nos quais imperam o atraso nas relações de produção e de trabalho, a precariedade e os efeitos nocivos do êxodo rural (Zanoni e Lamarche, 2001; Wanderley, 2004). Para os formuladores do DTS, as regiões 
rurais precisam redefinir seu próprio estatuto, passando a ser consideradas espaços heterogêneos e portadores de capacidades ainda pouco exploradas ou valorizadas pela sociedade. Essa transformação pode favorecer a mobilização de seus ativos para a promoção de inovações sociais (Andion, 2014) capazes de demonstrar todo o potencial de seu dinamismo demográfico, geográfico, socioeconômico e socioambiental (Veiga, 2002a).

Em síntese, pelas abordagens do DTS, o espaço rural não se restringe à atividade agrícola, de modo que sua transformação não interessa apenas a grupos sociais e setores específicos, devendo ser tratada como uma questão central na agenda de desenvolvimento do país. A superação dos inúmeros problemas de desenvolvimento no meio rural, sob esse enfoque, não ocorrerá a partir do isolamento, mas por meio de articulação com os aglomerados urbanos próximos, possibilitando pensar e colocar em prática soluções inovadoras que promovam novos estilos de desenvolvimento, socialmente mais includentes e sustentáveis.

Os debates sobre os novos rumos do rural - que redescobre e redefine seus valores e significados - e sobre as dinâmicas de DTS acabam influenciando o desenho dos programas e políticas públicas voltadas para o desenvolvimento rural. As duas últimas décadas são marcadas por uma transição no processo de planejamento do desenvolvimento rural, de uma lógica de repartição setorial e de "balcão", para uma lógica "territorial e de projetos" (Beduschi Filho e Abramovay, 2004:6) e de uma abordagem predominantemente economicista para uma perspectiva de sustentabilidade (Vieira et al., 2010a; Jean, 2010).

A adoção das perspectivas da territorialidade e da sustentabilidade na agenda das políticas públicas rurais exige que sejam construídas novas institucionalidades e novas formas de governança para o planejamento e a gestão do desenvolvimento rural. Dito de outra forma, a promoção do DTS pressupõe interação, diálogo e compartilhamento de decisão e responsabilidades entre representantes governamentais e da sociedade civil (Vieira et al., 2010a; Sencébé, 2010). Esse processo de "coprodução do bem público" (Ostrom, 1996; Marshall, 2004; Pestoff, 2006; Bovaird, 2007; Vaillancourt, 2009; Salm e Menegasso, 2010) não é dado a priori, pois é fruto de uma construção coletiva. Como afirma Zuindeau (2000), a "sustentabilidade territorial” é uma mistura de normas e limites exógenos que tomam forma por meio dos arranjos sociais; esses últimos são consequência das especificidades do território e, sobretudo, da "ação coletiva" dos atores locais (Cefaï, 2007, 2009; Gohn, 2007), composta por representações, formas de regulação/coordenação e relações de forças particulares.

Diante dessa problemática, o propósito do presente artigo consiste em analisar como o processo de coprodução é construído na prática, por meio de estudo do caso de implantação do Colegiado de Desenvolvimento Territorial (Codeter) na região da Serra Catarinense. Esse Colegiado abrange um universo de 18 municípios de Santa Catarina, englobando as microrregiões de Lages e São Joaquim, conforme figura 1. Particularmente, pretendemos: (i) discutir como o Codeter surge e se institucionaliza na região; (ii) examinar como essa institucionalização se consolida, por meio da ação coletiva empreendida pelos diferentes atores que compõem o referido colegiado; e (iii) analisar em que medida essa ação coletiva contribui para promoção da coprodução do bem público. 
Figura 1

Municípios pertencentes ao território da Serra Catarinense

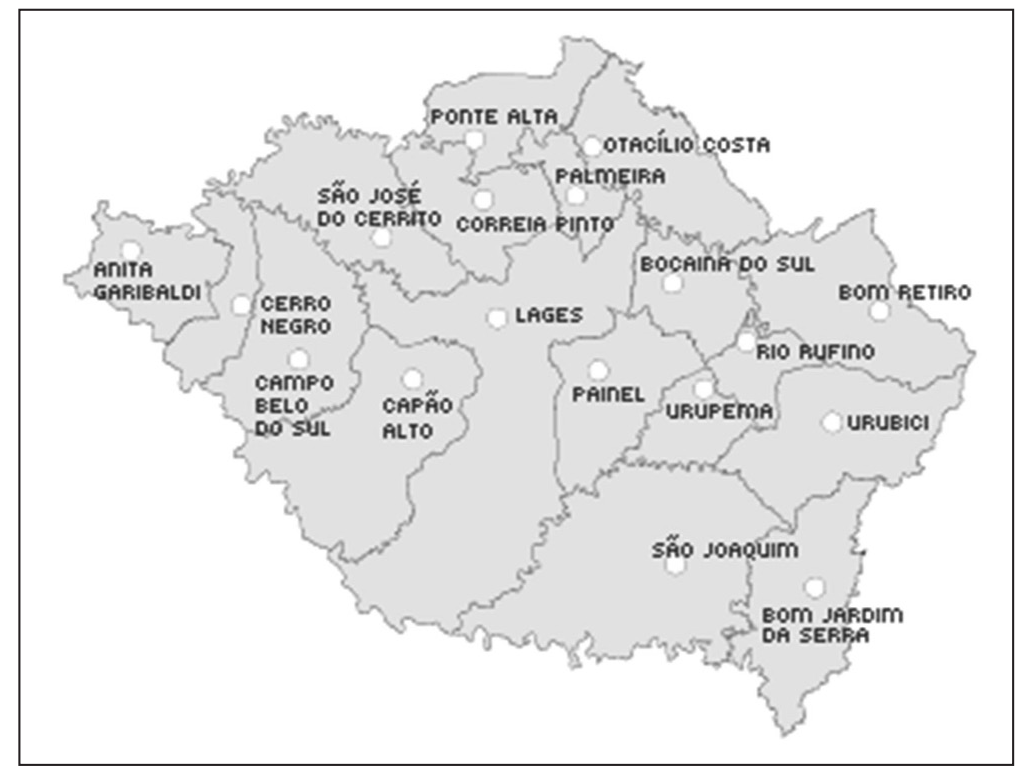

Fonte: PTDRS Serra Catarinense (2011).

Este artigo tem como pano de fundo o Programa Nacional de Apoio aos Territórios Rurais (Pronat), cujas ações são voltadas ao fortalecimento do meio rural nas regiões menos desenvolvidas do país. Criados a partir de 2003, pela Secretaria de Desenvolvimento Territorial (SDT) do Ministério do Desenvolvimento Agrário (MDA), os territórios rurais do Pronat abrigam os Codeteres, que são órgãos de deliberação colegiada de caráter permanente, representativos e participativos de planejamento e articulação de iniciativas para o DTS. Sua principal atribuição é oferecer suporte político, organizacional e técnico para um território rural, buscando promover o debate e a articulação de políticas públicas rurais entre os municípios (PTDRS Serra Catarinense, 2011). Embora em termos operacionais atue de maneira vinculada à SDT/MDA, o Codeter se constitui num espaço de interação e expressão de diferentes formas de poder: o poder político-administrativo dos agentes públicos, o poder representativo dos sindicatos rurais, o poder técnico das instituições de pesquisa e extensão rural, e, por fim, o poder participativo das Organizações da Sociedade Civil (OSCs) ligadas ao setor da agricultura familiar.

Em função do grande número de organizações integrantes do Codeter da Serra Catarinense, optou-se por concentrar a pesquisa em torno do Núcleo Gestor composto, de forma paritária, por 26 membros efetivos e 26 suplentes representantes do governo e da sociedade civil. Os 52 membros do Núcleo Gestor incluíam: (i) representantes governamentais no âmbito dos municípios das seguintes instituições: Prefeituras, Empresa de Pesquisa Agropecuária e Extensão Rural de Santa Catarina (Epagri) e Câmara dos Vereadores; (ii) representantes 
da sociedade civil no âmbito dos municípios, incluindo OSCs ligadas à agricultura familiar, associações de Microbacias, assentamentos, Conselhos Municipais de Desenvolvimento Rural (CMDRs) e sindicatos dos trabalhadores rurais; (iii) representantes de entidades governamentais e da sociedade civil ligadas ao desenvolvimento rural, com atuação regional, como: Universidades (Uniplac, Udesc e IFSCs), Epagris regionais, Associações de Municípios (Amures), Secretaria Regional de Desenvolvimento (SDR de Lages), Sindicatos (Fetraf Sul e Astraplan), Federação da Agricultura e Pecuária do Estado de Santa Catarina (Faesc), OSCs regionais como Centro Vianei (articulador da política no território) e a Cáritas, e organizações da economia social, como a Ecoserra.

Além destes, participaram também da pesquisa o articulador territorial - contratado pela OSC executora do contrato com o MDA para assessorar metodológica, técnica e operacionalmente o Codeter - e o articulador estadual, disponibilizado pelo MDA como consultor do território para organizar as ações do Colegiado em âmbito territorial e estadual.

A estratégia de investigação utilizada foi de cunho qualitativo, utilizando o método de estudo de caso descritivo e interpretativo (Yin, 2010). A pesquisa teve duração de 15 meses, sendo realizada de janeiro de 2011 a abril de 2012, incluindo quatro tipos de fonte de evidência: trabalho de campo, realização de entrevistas, aplicação de questionários e análise de documentos. O trabalho de campo teve duração de 10 meses (de março a dezembro de 2011) e envolveu a observação direta de oito reuniões do Codeter da Serra Catarinense e a realização de sete entrevistas com membros do Núcleo Gestor e seis com os atores externos que estão inseridos no contexto institucional de atuação do Codeter. Os membros externos entrevistados foram: o ex-articulador territorial contratado pelo Centro Vianei, o delegado do MDA em Santa Catarina, o consultor estadual contratado pela SDT/MDA (com atuação em outros territórios de Santa Catarina), o gerente regional da Epagri de Lages, o diretor de extensão rural e pesqueira da Epagri e o secretário executivo do Conselho Estadual do Programa Nacional de Fortalecimento da Agricultura Familiar (Pronaf).

Foram também aplicados questionários junto aos 52 membros titulares e suplentes do Núcleo Gestor. Desses, 19 responderam ao questionário, sendo 10 representantes do governo e nove da sociedade civil. Finalmente, a pesquisa envolveu também a análise de diversos documentos, tais como: atas de reuniões do Codeter, relatórios de consultoria e de oficinas territoriais, regimento interno do Codeter, PTDRS, entre outros.

Após a sistematização dos dados, esses foram examinados à luz do referencial teórico sintetizado no item a seguir, no qual relacionamos os conceitos de "coprodução do bem público" e de "ação coletiva" norteadores do estudo — , dando origem aos resultados apresentados posteriormente. Tais resultados incluem uma narrativa sobre a trajetória de institucionalização do Codeter da Serra Catarinense e a análise dos elementos constitutivos da ação coletiva promovida pelos atores que dele fazem parte. Com base nessa análise, buscamos, então, elucidar em que medida essa ação coletiva contribuiu para engendrar dinâmicas de coprodução do bem público. Para concluir, são feitas algumas considerações finais sobre o caso, de modo a produzir generalizações que possam subsidiar novos estudos. 


\section{Coprodução do bem público como ação coletiva}

Na década de 1970 surgem os primeiros estudos científicos sobre a coprodução do bem público, sendo os norte-americanos os pioneiros nesse campo. Desde então, o tema ganha expressão passando a ser estudado em centros de pesquisa de diversos países, a exemplo da Austrália, Estados Unidos, Holanda, Inglaterra, Itália, Portugal e Brasil (Ostrom, 1996). Segundo Bovaird (2007), o termo coprodução, embora ainda não seja suficientemente conhecido, está presente em muitas das atividades da administração pública contemporânea. Todavia, como no campo teórico o termo é considerado recente, não possui ainda uma definição precisa e universalmente aceita pelos pesquisadores (Salm e Menegasso, 2010).

Para Vaillancourt (2009), a coprodução ocorre quando o Estado não está sozinho na tarefa de gerir as políticas públicas, dividindo essa responsabilidade com organizações do setor privado, do terceiro setor ou de ambos simultaneamente. A coprodução está, então, associada ao compartilhamento de poderes e responsabilidades entre agente públicos e cidadãos na produção de bens e serviços públicos (Pestoff, 2006).

Quando o termo foi criado, a argumentação principal era de que a coprodução seria uma estratégia para aumentar a efetividade e diminuir os custos do Estado na prestação de serviços públicos. Autores como Bjur e Siegel (1977), Kiser e Percy (1980), Whitaker (1980), além de Bruney e England (1983) defendiam esta perspectiva, entendendo que os custos dos serviços diminuem à medida que os cidadãos se engajam na sua produção. De acordo com Brudney e England (1983), a coprodução envolve um mix de atividades que os agentes públicos e cidadãos realizam em conjunto para prover a melhoria da eficiência dos custos e da qualidade dos serviços públicos, em tempos de dificuldades fiscais do Estado.

Contudo, tais autores não manifestavam explicitamente o entendimento de que a coprodução é também uma estratégia para proporcionar descentralização do poder e gerar mecanismos para aumentar o envolvimento dos cidadãos na esfera pública. As questões de participação cívica eram praticamente ausentes nas análises desses autores.

Essa ideia inicial a respeito da coprodução foi posteriormente criticada no campo da administração pública (Salm e Menegasso, 2010). Por conta disso, um segundo grupo de autores passa a tratar o tema sob outro ângulo. Para eles, a coprodução envolve propósitos políticos, além dos econômicos. Há uma reorientação da ênfase exclusiva em eficiência e interesse para um foco que recupera os valores de cidadania. Nesse sentido, a coprodução seria uma estratégia para que organizações da sociedade civil, movimentos sociais e lideranças comunitárias compartilhassem a responsabilidade da solução dos problemas públicos, por meio de um processo de deliberação coletiva (Klein Jr. et al., 2012). Dentre os autores dessa corrente destacam-se Sundeen (1985), Levine (1984), Ostrom (1996), Marshall (2004), Bovaird (2007), Pestoff (2006, 2009) e Vaillancourt (2009).

Levando em conta esse debate, não nos concentraremos aqui na definição da coprodução do bem público a partir de uma leitura teórico-normativa. Buscaremos focalizar nossa análise na sua prática, comprendendo o fenômeno como uma outra forma de exercício da ação pública. Essa ação pública de novo tipo emerge num contexto no qual o Estado "perde o 
monopólio de produção e proteção do bem público e amplia-se a complexidade do sistema de decisão sobre o fazer política" (Milani, 2008:558). Como afirma o autor, o papel do governo ainda é central, mas ele passa a fazer parte de sistemas de governança mais amplos. A ação pública então se reconfigura e pode ser compreendida como uma "ação coletiva" em que os atores governamentais e não governamentais tomam parte.

Nesse sentido, a coprodução pode ser vista como um fenômeno que ocorre em diferentes níveis de intensidade e sua manifestação prática depende do espaço disponibilizado à participação, ao diálogo e ao compartilhamento dos poderes decisórios, bem como do modelo de governança adotado (Salm e Menegasso, 2010). O tipo de coprodução depende essencialmente "de quem", "como" e "em que intensidade" os cidadãos se mobilizam e se envolvem na busca de soluções para os problemas públicos. Dessa forma, para que seja possível analisar a coprodução, algumas variáveis importantes devem ser observadas, como: a diversidade de atores; a legitimidade da ação; o engajamento cívico com os problemas públicos; e o empoderamento da sociedade civil para deliberação pública.

Para examinar como as dinâmicas de coprodução são concebidas e construídas na prática pelos atores do Colegiado, torna-se então necessário recorrer a uma teoria da ação que permita analisar empiricamente como estes se mobilizam, codefinem e constroem soluções em colaboração para os problemas públicos do território (Cefaï, 2009). Nessa perspectiva, a noção de "ação coletiva" e as teorias que tratam desse fenômeno são muito úteis para o presente trabalho.

Desde o início do século passado, a ação coletiva tem sido exaustivamente analisada pelos estudiosos da sociologia e da ciência política. Como mostra Cefaï (2007), o campo de estudos sobre as ações coletivas é antigo e vasto, composto por diferentes paradigmas. Cada paradigma é tributário das tradições científicas e dos debates contemporâneos em cada região. As diferentes visões sobre a ação coletiva foram construídas a partir de abordagens teóricas e contextos institucionais e geográficos distintos, que nem sempre dialogaram entre si. Cada perspectiva se desenvolveu, portanto, em relativo isolamento já que até recentemente havia pouca interação entre elas.

Em função dessa diversidade, é difícil construir uma síntese de descrições e conceitos acerca do termo. Uma definição ao mesmo tempo sintética e abrangente foi dada por Cefaï (2007:8). Para esse autor, a ação coletiva pode ser definida como "a tentativa de constituição de um bem coletivo, mais ou menos formalizado e institucionalizado, por indivíduos que buscam alcançar um objetivo partilhado em um contexto de cooperação e competição com outros coletivos".

Com base nessa definição, buscaremos analisar a ação coletiva do Codeter sem tomar como definitivo um único modelo de análise. Isso implica considerar as principais contribuições dos diferentes paradigmas da ação coletiva, bem como seus limites, buscando construir passarelas e possibilidades de diálogo entre eles, as quais permitiriam uma maior compreensão do fenômeno estudado. Foi nesse espírito que se utilizou as referências do campo de estudos da ação coletiva. Considerando as limitações de páginas e a amplitude do tema, não será possível aprofundar a discussão em cada um dos paradigmas que dominam esse campo. Entretanto, apresenta-se no quadro 1 uma síntese desses paradigmas com base nos trabalhos exaustivos elaborados por Cefaï (2007) e Gohn (2007). 


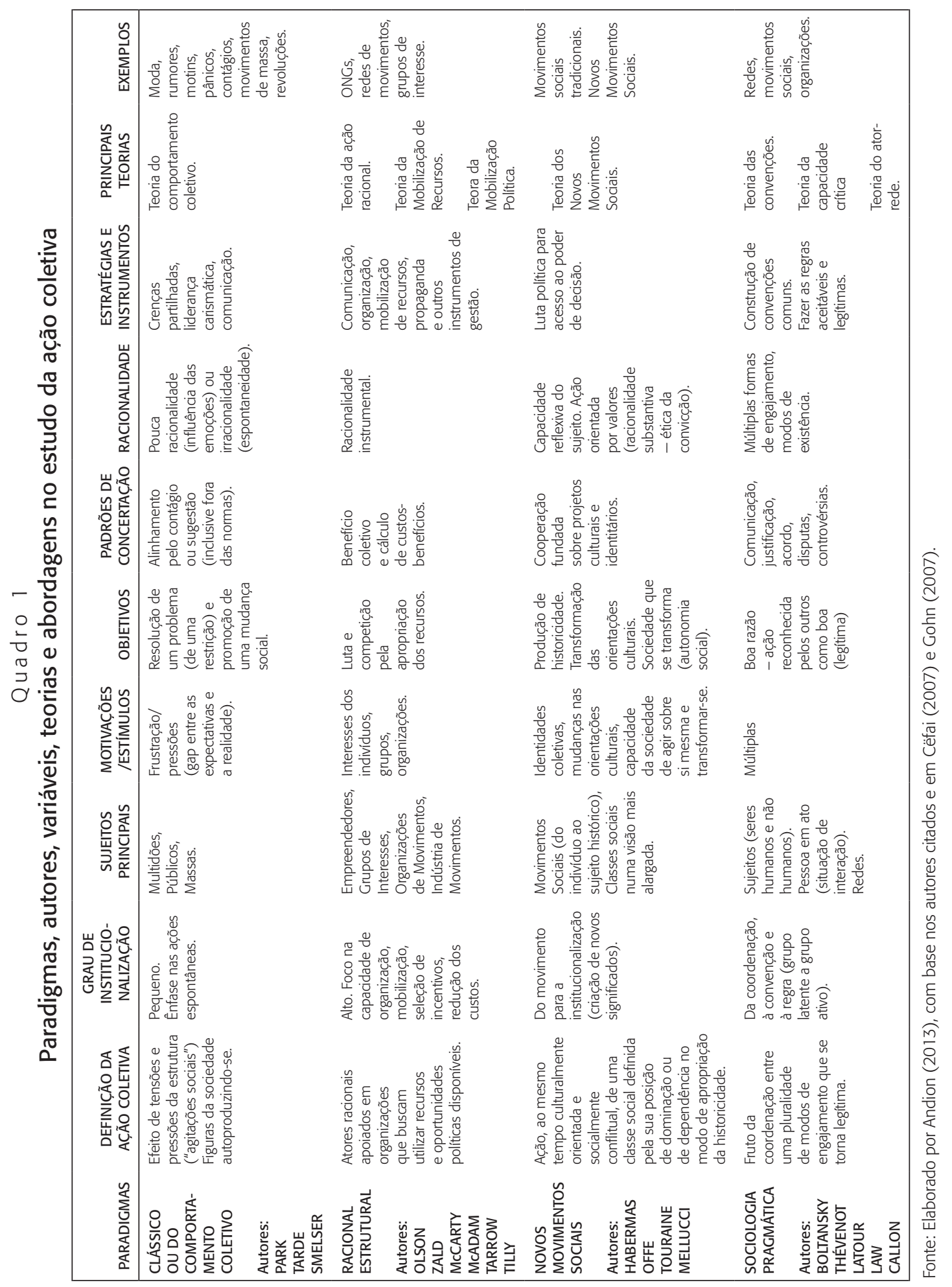

Rev. Adm. Pública - Rio de Janeiro 49(1):119-140, jan./fev. 2015 
Com base na sociologia pragmática, a abordagem teórica-analítica adotada neste artigo parte do pressuposto de que é possível fazer dialogar os paradigmas elencados no quadro 1 , considerando as suas particularidades e diferenças, na análise da ação coletiva aqui estudada. Isso porque toda ação coletiva possui uma dimensão racional/instrumental (que se relaciona com o "como" ela se produz — que atores, estratégias, instrumentos, recursos e outros fatores convergem para a sua existência) e, por outro lado, possui também uma dimensão simbólica (histórica, política e cultural que explica "por que" e "para que" ela ocorre — relacionando-se com questões de contexto, de causa e de identidade da ação coletiva).

Sob o guarda-chuva da sociologia pragmática se inserem diferentes abordagens que incluem: a economia das convenções (Aglietta e Orlean, 1982; Livet e Thévenot, 1994; Reynaud, 2004), a teoria da capacidade crítica (Boltansky e Thévenot, 2006) e a teoria do atorrede (Latour, 2012). A sociologia pragmática assume um papel de destaque em várias partes do mundo no século XXI, representando uma nova visão da sociologia que (re) valoriza as práticas e os processos sociais e os indivíduos que os protagonizam. Ela propõe um novo enfoque em termos de teoria de ação, buscando superar algumas dicotomias clássicas da sociologia, tais como: indivíduo $\times$ coletivo; ator $\times$ estrutura; valor $\times$ interesse; e racionalidade $\times$ norma.

Nesse enfoque, a ação coletiva só é possível "se a conjunção dos atos permite constatar uma certa ordem, uma certa coordenação" (Livet e Thévenot, 1994:139). Nesse sentido, compreender como se constrói essa coordenação torna-se essencial para entender se há ou não coprodução e, para tanto, é importante considerar os elementos comunicativos, relacionais e práticos que tornam a coordenação possível. Isso implica identificar, de uma forma bem realista, quais são os aspectos que aproximam ou dividem os membros do Codeter em torno do desenvolvimento rural no território da Serra Catarinense, analisando, assim, os processos pelos quais esses atores se engajam na superação dos problemas públicos do território.

\section{Trajetória de institucionalização do Codeter da Serra Catarinense}

Durante os primeiros anos de funcionamento do Pronat, o território da Serra Catarinense abrangia as microrregiões de Campos Novos, Curitibanos, Lages e São Joaquim, englobando um total de 31 municípios. Para gerir esse amplo território, denominado de Planalto Serrano Catarinense, foi implantada a Comissão de Implantação de Ações Territoriais (Ciat), no intuito de aumentar o grau de institucionalidade do DTS na região e apoiar iniciativas da sociedade civil e dos poderes públicos que caminhavam nessa direção.

A Ciat foi formada em 2004 e para sua estruturação foram contatadas as principais entidades ligadas ao desenvolvimento rural da região. A seleção dos primeiros representantes para compor a Ciat foi feita por consenso entre as instituições presentes nas primeiras oficinas territoriais, sem o uso de critérios preestabelecidos. Também não foram acordadas regras que garantissem igual participação de todos os municípios e instituições representativas do território. 
Após as primeiras oficinas ficou definido que a Ciat seria composta por 33 membros titulares com mandato temporário e que duraria até a instalação definitiva do Codeter. Observa-se que a maioria das instituições públicas e privadas selecionadas era do setor agrícola, tendo sua atuação voltada à agricultura familiar.

Após alguns anos de atuação da Ciat, seus membros optaram pela criação do Codeter do Planalto Catarinense. Pela primeira vez, a composição passava a ter critérios formalizados que previam uma participação equilibrada dos municípios. Percebe-se que, na consolidação do Codeter, houve então um aprendizado sobre o processo de participação. Entretanto, somente o número de municípios participantes no colegiado foi ampliado e a escassa representação da diversidade rural/urbano continuou presente na composição do Colegiado.

A divisão do Território do Planalto Serrano Catarinense aconteceu em dezembro de 2006, após a oficina que previa a constituição do Codeter. Segundo os relatórios consultados, não foi possível aprovar o regimento interno do Colegiado, por haver profundas divergências em relação à abrangência do território. A grande maioria dos representantes das microrregionais de Campos Novos e Curitibanos defendia a manutenção de um único território, já os representantes das microrregionais de São Joaquim e Lages defendiam a sua cisão em dois. Para resolver o impasse teve-se que recorrer ao voto dos seus participantes. Por conta do resultado da assembleia, foi decidido que um território abrangeria os 18 municípios das microrregiões de Lages e São Joaquim, e outro, os 13 municípios das microrregiões de Curitibanos e Campos Novos.

Essa oficina territorial é considerada por muitos participantes da época como um marco. Foi a partir daí que se estabeleceu uma discussão mais profunda sobre a identidade do território entre os participantes. Os argumentos principais para a divisão do território giravam em torno do sentimento de não pertencimento. Os representantes de São Joaquim e de Lages não tinham a mesma visão daqueles de Campos Novos e de Curitibanos, especialmente quando se discutiam as estratégias a serem adotadas para reforçar o desenvolvimento territorial. É importante ressaltar que todos os representantes que participaram da pesquisa (por meio de entrevista ou questionário) afirmaram existir uma identidade comum nos municípios que atualmente fazem parte do território da Serra Catarinense.

Analisando a trajetória de implantação e consolidação do Codeter no território da Serra Catarinense, percebe-se claramente que a construção territorial (objeto do processo de coprodução aqui analisado) é fruto de um aprendizado coletivo. Não bastou a intenção do MDA e a implementação da política pública na região. A definição de território foi construída pelos atores locais, por meio de acordos e disputas reais. Entretanto, essa composição territorial não se constituiu a partir de um espaço amplo e aberto de negociação entre múltiplos atores e grupos estratégicos. O caso do Codeter mostra que essa composição foi fruto de uma arena de disputas, que, no caso analisado, já parte de uma segmentação (como visto, as instituições participantes são ligadas na sua grande maioria ao universo da agricultura familiar). Conforme Cazella e Búrigo (2008), apesar do discurso em defesa de ampla participação social, a Ciat do Planalto Catarinense não se constituiu como um espaço aberto para a negociação política envolvendo todos os diferentes atores ou grupos sociais presentes no território. 
Por outro lado, várias evidências demonstram que o Codeter teve um importante papel institucional no território. A totalidade dos atores pesquisados confirmou que o Colegiado trouxe melhorias para o território. A principal contribuição foi possibilitar a mudança da cultura do imediatismo e do interesse particular para um pensamento mais sistêmico, baseado no longo prazo. Nos primeiros anos da implantação da Ciat, existia uma disputa muito evidente entre os municípios para ver qual deles conseguia arrecadar mais recursos e projetos da política pública do MDA. A prioridade era obter incentivos financeiros para a aquisição de equipamentos ou para construção de estruturas locais. Somente depois de atendidos os interesses municipais e institucionais, os participantes se preocupavam com as formas de gestão, sustentabilidade e viabilidade dos projetos.

Segundo os entrevistados, os projetos atuais são aprovados sob critérios mais rígidos, nos quais se observa sua capacidade de fortalecer a estruturação do meio rural e sua viabilidade em termos de gestão, financeira e social. Além disso, a concepção do que são projetos territoriais também se ampliou. Atualmente, os representantes estão mais preocupados com o impacto intermunicipal, ou seja, com os benefícios que o projeto trará para o desenvolvimento do território. Assim, as demandas passaram a englobar cada vez mais os municípios, fato que levou a uma diminuição do número de projetos apresentados nas plenárias territoriais. Se em 2005 foram apresentados 24 projetos, que tinham, em sua maioria, a mesma área geográfica de atuação das organizações proponentes, em 2011 esse número caiu para apenas dois pleitos, cujas ações beneficiavam direta ou indiretamente todo o espaço territorial.

Outra mudança oportunizada pelo Codeter foi o aumento do nível de execução de políticas públicas federais e a consequente mobilização de recursos para os municípios da Serra Catarinense. Além do MDA, intensificaram-se as ações no Ministério da Agricultura, com a implantação do Sistema Unificado de Atenção a Sanidade Agropecuária (Suasa); no Ministério da Educação, com o Programa Nacional de Alimentação Escolar (PNAE); e no Ministério do Desenvolvimento Social, com o Programa de Aquisição de Alimentos (PAA).

Em suma, as diferentes evidências elencadas, tanto na trajetória como nos resultados promovidos pelo Codeter na região, permitem afirmar que este se tornou um espaço institucional legítimo de promoção do desenvolvimento rural na Serra Catarinense. Porém, esse processo de institucionalização não ocorreu de forma automática, a partir da oportunidade gerada pela política proposta pelo MDA. Ele se deu graças à formação gradual de uma ação coletiva que se engendra a partir da articulação dos atores locais; ou seja, há um processo de transformação de um grupo latente (a Ciat) num grupo ativo (Codeter). A política pública ganha vida e se reconfigura, na prática, a partir dessa ação coletiva, cujos componentes serão analisados a seguir.

\section{Ação coletiva no Codeter e seus elementos constitutivos}

As evidências da pesquisa permitiram constatar que a implantação e consolidação do Codeter da Serra Catarinense resultam da ação coletiva, já que se constitui numa tentativa de um co- 
letivo de atores (governamentais e da sociedade civil) de promover o desenvolvimento rural do território, em um contexto de cooperação e de competição com outros coletivos. A seguir são analisados alguns aspectos constitutivos dessa ação coletiva.

\subsection{Uma identidade coletiva construída em torno de cooperação e de conflitos}

Para os membros consultados, a identidade e o sentimento de pertencimento ao Codeter da Serra Catarinense foram construídos paulatinamente. Apesar de as aspirações individuais e corporativas ainda permearem a mobilização dos seus integrantes, o Codeter conseguiu forjar um espaço favorável para o encaminhamento dos problemas públicos. Esse clima de colaboração se expressa nos projetos territoriais propostos que, gradualmente, passam a focalizar demandas coletivas, e não apenas institucionais, e envolvem mais municípios, necessitando de uma mobilização e engajamento de mais atores em sua elaboração e implementação.

Vários projetos apresentados e aprovados no Codeter refletiam a identidade territorial, como os projetos para monitorar a qualidade de fabricação do Queijo Serrano, estruturar um entreposto de comercialização do mel e para construir uma serraria móvel para o corte do pinus e eucaliptos. Todas estas atividades econômicas e produtos são característicos da região. Além disso, os projetos aprovados e executados mais recentemente estão incluídos nos eixos estratégicos e linhas de ação do PTDRS.

Por outro lado, isso não eliminou os conflitos históricos em torno de temas polêmicos e que continuam sendo objeto de disputa dentro do Codeter. Um exemplo são as lutas entre os defensores do modelo de modernização da agricultura (convencional) e os defensores de uma agricultura mais sustentável. No âmbito do Colegiado da Serra Catarinense existe um debate intenso sobre a importância e o alcance das práticas agroecológicas na região, embora se saiba que apenas uma minoria dos agricultores do território é praticante efetiva da agroecologia.

Nas primeiras plenárias após a implantação do Codeter, ocorreram conflitos que retratavam bem as visões discordantes de seus participantes a respeito do futuro da agricultura familiar na região. Em determinado momento, os defensores de cada proposta se articularam em torno de três projetos distintos, a saber: o fortalecimento do arranjo agroecológico, o apoio à cadeia produtiva do leite e o incremento da cadeia produtiva do vime. Como não havia consenso, a definição dos apoios parecia que somente poderia ser decidida no voto, com a consequente "derrota" dos perdedores. A solução sugerida pelo articulador territorial foi de que era possível aprovar as duas ações. Ou seja, que era possível desenvolver atividades com produtores de leite convencional, estimulando processos de reconversão para a agroecologia, e também promover a criação de cooperativas e de iniciativas de comercialização dos produtos agroecológicos.

Esse exemplo nos permite constatar que a construção da identidade coletiva não se dá pela mera soma dos interesses ou ainda por um consenso simples. Essa identidade vem sendo construída por meio do reconhecimento dos distintos interesses e pelo conflito e negociação

entre eles. É esse embate que possibilita a construção de objetivos comuns. Segundo Reynaud 
(2004), os conflitos representam um avanço na construção de uma ação coletiva, pois eles obrigam uma negociação entre as partes na tentativa de solucionar o problema.

\subsection{Múltiplas motivações e formas de engajamento}

A motivação principal para participação, para a maioria dos membros entrevistados, ainda é a possibilidade de acessar mais recursos para seu município e/ou instituição. Embora haja uma motivação comum em buscar o desenvolvimento e qualidade de vida no meio rural, é a maximização dos ganhos particulares que muitas vezes leva os atores e instituições a participarem do Codeter.

Porém, quando investigamos mais a fundo, percebemos que os diferentes representantes das instituições participantes justificam de forma particular porque participam do Codeter. Os representantes da associação dos municípios (Amures) expressam interesse em aproveitar o espaço do Codeter para melhorar a sua relação com as organizações da sociedade civil em seu território. A OSC que atua como articuladora da política no território objetiva inserir o tema da agroecologia na agenda de desenvolvimento da região. Os representantes da Epagri manifestam a preocupação de promover benefícios para as famílias rurais, consolidando-as cada vez mais no campo. Em suma, cada um dos atores institucionais entrevistados age por uma "boa razão" (Reynaud, 2004), ou seja, apresenta uma motivação própria que se reflete em suas formas de engajamento.

O que se observa é que os atores se engajam no Codeter não apenas com base na mera "razão do cálculo" (para ter acesso a mais recursos), nem apenas por um "bem comum" (promover o desenvolvimento do território). O ator age baseado em "uma boa razão" que dá significado a sua ação e a torna pertinente, coerente e consequente. É nesse encontro de "boas razões" que os objetivos e projetos comuns parecem emergir. Desse modo, percebe-se no Codeter a coexistência de múltiplas visões sobre o desenvolvimento rural que negociam, dando lugar aos projetos que são priorizados e colocados em prática.

\subsection{Múltiplas noções do "bem público" e das formas como alcançá-lo}

A comparação entre os primeiros projetos aprovados no âmbito do território com os mais recentes permite afirmar que a compreensão do Colegiado a respeito dos problemas públicos ligados ao desenvolvimento rural e da forma como resolvê-los se modifica. Os projetos deixaram de ser exclusivamente voltados ao investimento no meio produtivo, passando a abranger outras áreas estratégicas para o desenvolvimento rural, como a habitação, a comunicação social, a educação e a saúde no campo.

Porém, as divergências em relação às prioridades permanecem presentes. Essas divergências indicam que não existe um significado único de desenvolvimento rural no âmbito do Colegiado. Alguns grupos de representantes entendem que as ações da política territorial de- 
vem se dar em torno do crescimento econômico do meio rural, buscando projetos que possibilitem gerar mais renda para o agricultor. Esses representantes estão preocupados em manter o agricultor familiar no campo com qualidade de vida, mediante o investimento em infraestrutura básica e em capacitação técnica. Outros grupos têm uma visão mais abrangente, enxergando que as ações territoriais voltadas ao desenvolvimento rural devam ir além da dimensão econômica, atendendo também as demandas ambientais, sociais e político-institucionais da região. Tais grupos também buscam meios de manter o agricultor no campo com qualidade de vida, mas entendem que o desenvolvimento rural não pode ser alcançado somente pela melhoria nas condições de infraestrutura e na capacidade de gerar renda. Envolvem também questões ligadas à saúde, educação, meio ambiente, transporte, segurança, serviços e outras atividades não agrícolas no campo.

Portanto, percebe-se que a compreensão do desenvolvimento rural não é a mesma para os diferentes atores pesquisados. Não há "uma" causa comum — nesse caso, uma noção compartilhada do desenvolvimento rural - que precede a ação coletiva e que mantém o grupo coeso, como defendem os teóricos dos Novos Movimentos Sociais. Percebe-se então que a ação coletiva aqui não é fruto de uma "única lógica de ação" definida a priori. Como afirmam Boltansky e Thévenot (2006) nas suas operações de julgamento os atores agem com base em vários "mundos comuns" que se esbarram, conflitam e negociam nas situações de ação coletiva. Isso fica evidente no caso aqui analisado, no qual se identificam visões divergentes acerca do desenvolvimento rural. Assim, o "bem comum" vem sendo construído por meio do reconhecimento dessas distintas visões e pelo conflito e negociação entre elas. Como destacam Reynaud (2004) e Cefaï (2009), na medida em que os atores se engajam na solução do problema público, eles definem com mais clareza os interesses coletivos ligados a projetos concretos.

\subsection{Aprendizado das regras}

Ao longo da trajetória de implantação do Codeter foram construídos algumas regras e critérios técnicos para melhorar a escolha dos projetos territoriais, o que denota um aprendizado coletivo. Em 2004, no primeiro ano de votação dos projetos com abrangência territorial, quase não havia regras e critérios estabelecidos. Ainda não existiam instâncias regionais ou municipais para debater os projetos com antecedência, nem era garantida a representação de cada município e microrregião do território na comissão da Ciat. Em 2005, a escolha dos projetos territoriais foi mediada por alguns critérios técnicos e considerou a participação de 10 representantes para cada microrregião do território. Em 2007, com a instalação do Codeter da Serra Catarinense, todos os 108 representantes municipais eleitos do Codeter tiveram o direito a participar e votar para escolha dos projetos territoriais. A escolha dos projetos nesse ano envolveu a participação de muito mais atores e incluiu representantes de todos os municípios do território, diferentemente dos anos anteriores. 
No início da implantação da Ciat no território do Planalto Serrano, não existia um regimento com critérios e regras escritas e acordadas entre os participantes. Por conta disso, os conflitos ficavam muito mais difíceis de serem mediados pelos articuladores territoriais e consultores governamentais do MDA. Segundo os autores da sociologia pragmática, quando são acordadas regras, o processo de gestão fica muito mais fácil de ser realizado. A legitimidade das decisões tomadas no colegiado, perante governo e sociedade civil, é facilitada por existirem regras compartilhadas, compreendidas e aceitas por todos os envolvidos (Reynaud, 2004).

\section{Avanços e limites na direção da coprodução para o desenvolvimento rural}

As evidências da pesquisa de campo revelaram que a ação coletiva empreendida no Codeter configura-se como um processo de coprodução entre governo e representantes da sociedade civil, na tentativa de responder aos desafios do desenvolvimento rural na região. Entretanto, como explorado anteriormente, o grau de coprodução resultante é consequência de uma série de variáveis que serão analisadas a seguir.

\subsection{Engajamento com os problemas públicos locais}

A ação coletiva do Codeter contribuiu para modificar a visão política e o envolvimento dos atores locais (públicos e privados) com projetos concretos, visando promover o desenvolvimento rural. Essa transformação ocorre principalmente nas ações territoriais que são desenvolvidas nos municípios, com vistas a garantir a implantação dos projetos. Percebe-se que os representantes locais acompanham de perto as iniciativas que foram decididas territorialmente, não transferindo totalmente as responsabilidades quanto a sua execução à Prefeitura ou outros órgãos municipais.

Um exemplo disso foi a implantação no território do programa federal Arca das Letras do MDA. Após ser discutido no espaço do Codeter, cada representante municipal articulou com as associações e órgãos locais de seu município a organização de um lugar para receber os kits com livros para estruturação de sua biblioteca rural. Estas bibliotecas continuam funcionando até hoje nas casas dos agricultores.

\subsection{Diversidade de atores}

Na composição do Núcleo Gestor não existe muita variedade de instituições governamentais representando o Codeter nos municípios. As vagas são basicamente destinadas aos escritórios municipais da Epagri e às prefeituras, que são geralmente representadas pela secretaria municipal de agricultura. Já os representantes da sociedade civil espelham uma maior diversidade. Associações civis de comunidades rurais, associações de microbacias, assentamentos rurais, 
sindicatos rurais e conselhos municipais de desenvolvimento rural possuem assento no Colegiado. Essa situação demonstra que o Núcleo dá voz para alguns atores que estão frequentemente na periferia da cena política municipal. Apesar dessa abertura, em grande parte dos municípios, o sindicato de trabalhadores rurais é ainda a representação civil mais usual.

Essa homogeneidade na representação do Codeter, principalmente das entidades do governo, não contribui para um processo de coprodução do bem público de alta intensidade, já que os atores participantes não representam a diversidade social existente no meio rural da região. As entidades participantes representam, em sua grande maioria, o segmento social dos agricultores familiares. Aliás, esse problema se repete na maioria dos territórios, ou seja, envolve a própria política territorial do MDA. Segundo as regras do programa federal, os projetos territoriais devem atender prioritariamente o público beneficiário das ações do MDA, ou seja, os agricultores familiares, assentados da reforma agrária, quilombolas, indígenas, pescadores artesanais e extrativistas. Além de contemplar em menor intensidade os agricultores familiares não considerados típicos, exclui geralmente os demais atores que não estão ligados às atividades produtivas do meio rural.

\subsection{Tipos de participação}

Muitas vezes as reuniões do Núcleo Gestor do Codeter tinham pautas muito extensas, compostas em sua maioria por demandas do MDA e por informes dados pelos articuladores territorial e estadual. Com isso, era disponibilizado pouco tempo para as discussões estratégicas.

Observou-se também uma repetição dos representantes que compareciam e explanavam suas ideias nas reuniões do Núcleo Gestor do Codeter. Essa participação era mais frequente entre os representantes governamentais. A baixa presença dos representantes civis pode ser explicada pelo pouco incentivo que eles recebiam para participar das reuniões, seja das suas organizações, seja do governo. Muitas delas, inclusive, tinham dificuldade de transporte para as reuniões.

Quanto ao grau de participação nas discussões, pode-se dizer que está diretamente associada ao grau de qualificação dos representantes. As entidades da sociedade civil que possuíam um nível menos estruturado de organização participavam menos das reuniões e seus representantes, em geral, tinham dificuldades para apresentar argumentos em defesa de suas "boas razões" junto aos demais membros do Colegiado. Esses representantes deliberavam sobre algumas decisões específicas do Colegiado, como a aprovação dos projetos territoriais (quando votavam), porém as principais deliberações continuavam sob a responsabilidade das lideranças de governo ou de OSCs mais estruturadas. Esse é um dos dilemas para participação direta dos cidadãos, segundo Roberts (2004). Para a autora, convidar todos os atores à mesa para debater como iguais em um processo de aprendizagem, e dando-lhes as ferramentas e recursos que eles precisam para serem bem-sucedidos, é um dos maiores desafios para participação direta dos cidadãos. 
Já os representantes das OSCs mais estruturadas e organizadas, principalmente daquelas com atuação regional, tinham uma participação mais interativa, conseguindo formar parcerias e negociar acordos com os representantes governamentais. O empoderamento desse grupo de representantes é alto, pois eles conseguem dialogar e sugerir propostas de forma horizontal e igualitária com os representantes do poder público. Por conta disso, a legitimidade da ação coletiva é maior. Há muito mais aceitação e compromisso com as deliberações tomadas, se comparado com os representantes locais dos agricultores.

As evidências tratadas anteriormente permitem verificar que o Codeter se consolidou institucionalmente na região graças a uma ação coletiva engendrada pelos atores locais, a qual gerou um processo de coprodução do bem público. No entanto, o grau de coprodução apresentado no Colegiado pode ser considerado de baixa intensidade. Conforme foi demonstrado, nem todos os representantes possuem o mesmo grau de empoderamento e participam com a mesma intensidade. A homogeneidade de atores é também outro fator que contribui para essa conclusão. Conforme visto, há um recorte setorizado na representação do Codeter, o que exclui a representação dos diferentes segmentos sociais pertencentes ao meio rural e desconsidera sua interface com o meio urbano, aspecto essencial na promoção de dinâmicas de DTS, como discutido na introdução.

\section{Considerações finais}

O artigo se propôs a examinar a trajetória de implantação do Codeter na Serra Catarinense e sua institucionalização na região, buscando analisar como esse processo ocorreu na prática, por meio da construção de uma ação coletiva pelos atores envolvidos, e em que medida essa ação coletiva engendrou dinâmicas de coprodução do bem público.

A análise do caso nos permitiu identificar e caracterizar a ação coletiva, mostrando que ela ocorre motivada não apenas por uma "causa comum" definida a priori, nem somente pela soma dos interesses individuais. Como afirma Reynaud (2004), os atores sociais não agem apenas para "maximizar interesses" ou ainda movidos por uma causa. Eles agem "por uma boa razão". Agir por uma boa razão para o autor consiste em postular ou reclamar a compreensão do outro sobre o sentido da ação. Esse sentido pode ser comunicado, partilhado e compreendido, por meio de negociação e do acordo. Desse modo, é por meio do conflito e da negociação que os membros do Codeter têm construído regras e convenções aceitas como legítimas.

Verificou-se, também, que a ação coletiva no Codeter oportunizou a ocorrência de um processo de coprodução do bem público; porém, o grau de coprodução observado foi de baixa intensidade. Existem alguns obstáculos e desafios enfrentados pelos gestores públicos para mobilização de um processo de coprodução do bem público mais denso no Codeter, tais como: o baixo empoderamento de alguns representantes da sociedade civil; a uniformidade dos segmentos sociais representados; e os diferentes graus de participação existentes entre eles. Entretanto, é importante lembrar que, como ação coletiva, a coprodução é fruto de um 
processo de aprendizado e existem importantes indicadores de que esse aprendizado vem ocorrendo ao longo dos anos. Por exemplo, os participantes hoje possuem um engajamento maior para resolução de problemas públicos, têm ampliado a sua compreensão quanto ao significado do desenvolvimento rural e construíram regras e critérios para ampliação da participação e representatividade dos atores municipais nas discussões territoriais.

Conclui-se, portanto, que a institucionalização e legitimação do Codeter — perante as principais entidades ligadas ao desenvolvimento rural do território - foi, em grande medida, facilitada por uma ação coletiva coordenada pelos articuladores territoriais e estaduais e "coproduzida" pelos representantes da sociedade civil e do governo, que negociaram e construíram acordos possíveis, em prol do que acreditam ser o desenvolvimento do território. Parafraseando Cefaï (2009:28), podemos afirmar que o Codeter se desenvolve ao mesmo tempo que promove o desenvolvimento do território da Serra Catarinese. Dessa maneira, se produzem critérios, a partir da experiência, que vão permitir a seus membros que se orientem, compreendam o que fazem e respondam às situações problemáticas, mediando processos de investigação, de experimentação e deliberação (com erros e acertos), rumo ao desenvolvimento rural.

\section{Referências}

ABRAMOVAY, Ricardo. Agricultura familiar e desenvolvimento territorial. Reforma Agrária., v. 28, n. 1, 2, 3, jan./dez. 1998, v. 29. n. 1, jan./ago. 1999.

ABRAMOVAY, Ricardo. Para uma teoria dos estudos territoriais. In: VIEIRA, Paulo F. et al. (Org.). Desenvolvimento territorial sustentável no Brasil. Subsídios para uma política de fomento. Florianópolis: Secco, 2010. p. 27-77.

AGLIETTA, Michel; ORLEAN, André. La violence de la monnaie. Paris: PUF, 1982.

ANDION, Carolina. Atuação das Organizações Não Governamentais (ONGs) nas dinâmicas de desenvolvimento no meio rural em Santa Catarina. In: VIEIRA, Paulo F. et al. (Org.). Desenvolvimento territorial sustentável no Brasil. Subsídios para uma política de fomento. Florianópolis: Secco, 2010. p. 329-373.

ANDION, Carolina. Inovação social. In: BOULLOSA, Rosana de F. (Org.). Dicionário para formação em gestão social. Salvador: Ciags, 2014. p. 98-101.

ANDION, Carolina. Paradigmas, autores, variáveis, teorias e abordagens no estudo da ação coletiva. Material didático elaborado para a disciplina organizações da sociedade civil e esfera pública do Programa de Mestrado em Administração. Florianópolis, 2013. Mimeografado.

ANDION, Carolina et al. Space and inequality: a case study of territorial development in Santa Catarina. Administrative Theory and Practice, v. 31, n. 1, p. 164-186, jun. 2009.

BEDUSCHI FILHO, Luiz C.; ABRAMOVAY, Ricardo. Desafios para o desenvolvimento de regiões rurais. Nova Economia, Belo Horizonte, v. 14, n. 3, p. 35-70, set./dez. 2004. 
BJUR, Wesley E.; SIEGEL, Gilbert B. Voluntary citizen participation in local government: quality, cost and commitment. Midwest Review of Public Administration, v. 11, n. 2, p. 135-149, jun. 1977. BOLTANSKI Luc; THÉVENOT, Laurent. On justification: economies of worth. Princeton; Oxford: Princeton University Press, 2006.

BOVAIRD, Tony. Beyond engagement and participation: user and community coproduction of public service. Public Administration Review, v. 67 , n. 5 , p. 846-860, set./out. 2007.

BRUDNEY, Jeffrey L.; ENGLAND, Robert E. Toward a definition of the coproduction concept. Public Administration Review, v. 43, n. 1, p. 59-65, 1983.

CAZELLA, Ademir A.; BÚRIGO, Fabio L. O desenvolvimento territorial no planalto catarinense: o difícil caminho da intersetorialidade. Revista Extensão Rural, v. 15, p. 5-30, jan./jun. 2008.

CEFAÏ, Daniel. Como nos mobilizamos? A contribuição de uma abordagem pragmatista para a sociologia da ação coletiva. Dilemas: Revista de Estudos de Conflito e Controle Social, Rio de Janeiro, v. 2, n. 4, p. 11-48, abr./maio/jun. 2009.

CEFAÏ, Daniel. Porquoi se mobilise-t-on? Les théories de l'action collective. Paris: Éditions La Découverte, 2007.

FERREIRA, Angela D. D.; ZANONI, Magda. Outra agricultura e a reconstrução da ruralidade. In: FERREIRA, Angela D. D.; BRANDENBURG, Alfio (Org.). Para pensar outra agricultura. Curitiba: Editora da UFPR, 1998.

FREITAS, Alan F. de et al. Mudanças conceituais do desenvolvimento rural e suas influências nas políticas públicas. Rev. Adm. Pública, v. 46, n. 6, p. 1575-1597, nov./dez. 2012.

GOHN, Maria da G. Teoria dos movimentos Sociais: paradigmas clássicos e contemporâneos. São Paulo: Loyola, 2007.

JEAN, Bruno. Do desenvolvimento regional ao desenvolvimento territorial sustentável. In: VIEIRA, Paulo F. et al. (Org.). Desenvolvimento territorial sustentável no Brasil. Subsídios para uma política de fomento. Florianópolis: Secco, 2010. p 49-76.

KISER, Larry L.; PERCY, Stephen L. The concept of coproduction and its implications for public service delivery. In: Workshop in political theory and policy analysis. San Francisco: Indiana University, abr. 1980. p. 13-16.

KLEIN JR, Vitor H. et al. Participação e coprodução em política habitacional: estudo de um programa de construção de moradias em SC. Rev. Adm. Pública, v. 46, n. 1, p. 25-48, jan./fev. 2012.

LATOUR, B. Reagregando o social: uma introdução à teoria do ator-rede. Salvador: Edufba, 2012.

LEVINE, Charles H. Citizenship and service delivery: the promise of coproduction. Public Administration Review, v. 44, p. 178-184, 1984.

LIVET, Pierre; THÉVENOT, Laurent. Les catégories de l'action collective. In: ORLÉAN, André (Org.). Analyse économique des conventions. Paris: Presses Universitaires de France, 1994. 
MARSCHALL, Melissa J. Citizen participation and the neighborhood context: a new look at the coproduction of local public goods. Political Research Quarterly, v. 57, n. 2, p. 231-244, jun. 2004.

MILANI, Carlos R. S. O princípio da participação social na gestão de políticas públicas locais: uma análise de experiências latino-americanas e europeias. Rev. Adm. Pública, Rio de janeiro, v. 42, n. 3, p. 551-579, maio/jun. 2008.

OLSON, Mancur. A lógica da ação coletiva: os benefícios públicos de uma teoria dos grupos sociais. São Paulo: Edusp, 1999.

OSTROM, Elinor. Crossing the great divide: coproduction, synergy and development. World Development, v. 24, n. 6, p. 1073-1087, 1996.

PESTOFF, Victor. Citizens and co-production of welfare services. Public Management Review, v. 8, n. 6, p. 503-519, 2006.

PESTOFF, Victor. Towards a paradigm of democratic participation: citizen participation and coproduction of personal social services in Sweden. Annals of Public and Cooperative Economics, v. 80, n. 2, p. 197-224, 2009.

PRETTY, Jules N. Participatory learning for sustainable agriculture. World Development, v. 23, n. 8, p 1247-1263, ago. 1995.

PTDRS SERRA CATARINENSE. Plano Territorial de Desenvolvimento Rural Sustentável do Território da Serra Catarinense. Lages: Codeter, 2011.

REYNAUD, Jean D. Préface. In: REYNAUD, Jean D. Les règles du jeu. L'action collective et la regulation sociale. Paris: Armand Colin, 2004. p. XII-XIX.

ROBERTS, Nancy. Public deliberation in an age of direct citizen participation. American Review of Public Administration, v. 34, n. 4, p. 315-353, dez. 2004.

SABOURIN, Eric. Desenvolvimento rural e abordagem territorial: conceitos, estratégias e atores. In: SABOURIN, Eric; TEIXEIRA, Olivio A. (Ed.). Planejamento e desenvolvimento dos territórios rurais. Brasília: Embrapa, 2002.

SACHS, Ignacy. Brasil rural da redescoberta à reinvenção. In: Estudos Avançados, São Paulo, v. 15, n. 43, p. 75-92, 2001.

SALM, José F.; MENEGASSO, Maria E. Os modelos de administração pública como estratégias complementares para a coprodução do bem público. Revista de Ciências da Administração, v. 11, n. 25, p. 68-96, set./dez. 2009.

SALM, José F.; MENEGASSO, Maria E. Proposta de modelos para a coprodução do bem público a partir das tipologias de participação. In: Anais do XXXIV ENANPAD. Rio de janeiro: Anpad, 2010. CD-ROM.

SCHNEIDER, Sergio. A pluriatividade na agricultura familiar. Porto Alegre: Editora UFRGS, 2003.

SENCÉBÉ, Yannick. Os territórios de desenvolvimento sustentável na França. Análise dos referenciais da descentralização e de suas traduções locais nos espaços rurais. In: VIEIRA, Paulo F. et al. 
(Org.). Desenvolvimento territorial sustentável no Brasil. Subsídios para uma política de fomento. Florianópolis: Secco, 2010. p. 411-424.

SUNDEEN, Richard. Coproduction and communities: implications for local administrators. Administration \& Society, v. 16, n. 4, p. 387-402, 1985.

VAILLANCOURT, Yves. Social economy in the co-construction of public policy. Annals of Public and Cooperative Economics, v. 80, n. 2, p. 275-313, 2009.

VEIGA, José E. da. Cidades imaginárias: o Brasil é menos urbano do que se calcula. Campinas: Autores Associados, 2002a.

VEIGA, José E. da. Desafios para o desenvolvimento do Brasil rural. In: IICA — Seminário, 2002b, São Luís. Disponível em: <www.econ.fea.usp.br>. Acesso em: 3 mar. 2006.

VIEIRA, Paulo F. et al. Introdução. In: VIEIRA, Paulo. F. et al. (Org.). Desenvolvimento territorial sustentável no Brasil. Subsídios para uma política de fomento. Florianópolis: Secco, 2010a. p. 5-24.

VIEIRA, Paulo F. et al. Potencialidades e obstáculos à construção de territórios sustentáveis em Santa Catarina. In: VIEIRA, Paulo. F. et al. (Org.). Desenvolvimento territorial sustentável no Brasil. Subsídios para uma política de fomento. Florianópolis. Secco, 2010b. p. 289-328.

WANDERLEY, Maria de N. B. Olhares sobre o 'rural' brasileiro. Raízes, Campina Grande, v. 23, n. 1/2, p. 82-98, jan./dez. 2004.

WHITAKER, Gordon P. Coproduction: citizen participation in service delivery. Public Administration Review, v. 40, p. 240-246, maio/jun. 1980.

WHITE, Sarah C. Depoliticising development: the uses and abuses of participation. Development in Pratice, v. 6, n. 1, p. 6-15, 1996.

YIN, Robert K. Estudo de caso: planejamento e métodos. 4. ed. Porto Alegre: Bookman, 2010.

ZANONI, Magda; LAMARCHE, Hugues. Agriculture et ruralité au Brésil: un autre modèle de développement. Paris. Karthala, 2001.

ZUINDEAU, Bertrand. Développement durable et territoire. Villeneuve d'Asq (Nord): Presses Universitaires du Septentrion, 2000.

Alexandre Coimbra Ribeiro é mestre em administração e analista da Empresa de Pesquisa Agropecuária e Extensão Rural de Santa Catarina (Epagri).E-mail: alexandreribeiro81@gmail.com.

Carolina Andion é doutora em ciências humanas e professora do Departamento de Administração Pública do Centro de Ciências da Administração e Socioeconômicas (Esag) da Universidade do Estado de Santa Catarina (Udesc). E-mail: andion.esag@gmail.com.

Fábio Burigo é doutor em sociologia política e professor do Departamento de Zootecnia e Desenvolvimento Rural do Centro de Ciências Agrárias (CCA) da Universidade Federal de Santa Catarina (UFSC). E-mail: fabio.burigo@ufsc.br. 